\title{
Katanin: A Sword Cutting Microtubules for Cellular, Developmental, and Physiological Purposes
}

\author{
Ivan Luptovčiak, George Komis, Tomáš Takáč, Miroslav Ovečka and Jozef Šamaj*
}

Department of Cell Biology, Centre of the Region Haná for Biotechnological and Agricultural Research, Faculty of Science,

Palacký University, Olomouc, Czechia

KATANIN is a well-studied microtubule severing protein affecting microtubule organization and dynamic properties in higher plants. By regulating mitotic and cytokinetic and cortical microtubule arrays it is involved in the progression of cell division and cell division plane orientation. KATANIN is also involved in cell elongation and morphogenesis during plant growth. In this way KATANIN plays critical roles in diverse plant developmental processes including the development of pollen, embryo, seed, meristem, root, hypocotyl, cotyledon, leaf, shoot, and silique. KATANIN-dependent

OPEN ACCESS

Edited by:

Marisa Otegui,

University of Wisconsin-Madison,

United States

Reviewed by:

Ram Dixit,

Washington University in St. Louis,

United States

Henrik Buschmann,

University of Osnabrück, Germany

*Correspondence:

Jozef Šamaj

jozef.samaj@upol.cz

Specialty section:

This article was submitted to

Plant Cell Biology

a section of the journal

Frontiers in Plant Science

Received: 01 September 2017 Accepted: 03 November 2017

Published: 21 November 2017

Citation:

Luptovčiak I, Komis G, Takáč T,

Ovečka M and Šamaj J (2017)

Katanin: A Sword Cutting

Microtubules for Cellular,

Developmental, and Physiological

Purposes. Front. Plant Sci. 8:1982.

doi: 10.3389/fpls.2017.01982 microtubule regulation seems to be under the control of plant hormones. This minireview provides an overview on available KATANIN mutants and discusses advances in our understanding of KATANIN biological roles in plants.

Keywords: cytoskeleton, katanin, microtubules, morphogenesis, plant development, cell division, cell growth, hormone

\section{INTRODUCTION}

KATANIN is a conserved AAA ATPase protein complex severing microtubules and it was discovered in Xenopus laevis (McNally and Vale, 1993). KATANIN is a heterodimer formed from catalytic p60 and regulatory p 80 subunits while its severing activity requires hexamerization on the microtubule surface (Hartman and Vale, 1999; Stoppin-Mellet et al., 2007). Catalytic p60 subunit represents a microtubule-stimulated ATPase that requires ATP hydrolysis to sever microtubules. The exact timing of severing is not well-understood since KATANIN likely moves along the microtubule before severing it (Eckert et al., 2012). Factors that may specify the KATANIN-mediated microtubule severing include microtubule lattice defects (Davis et al., 2002; Díaz-Valencia et al., 2011; Jiang et al., 2017), tubulin post-translational modifications (Sudo and Baas, 2010), and the occurrence of free tubulin dimers which may inhibit KATANIN activity through their carboxyl terminal tails (Bailey et al., 2015). The power stroke leading to microtubule severing is depending on a nucleotide-based transition of KATANIN oligomers between an open spiral structure (all p60 protomer nucleotide binding sites are occupied by ATP) and a closed, nucleotide devoid, ring structure that requires ATP hydrolysis (Zehr et al., 2017). Regulatory p80 subunit is a WD40-containing protein which is stimulating the microtubule severing activity of the p60 subunit and in animal cells is thought to mediate KATANIN targeting to specific sites such as the centrosome while potentiating microtubule binding (e.g., McNally and Vale, 1993; Hartman et al., 1998; McNally et al., 2000). The plant p60 subunit suffices for microtubule severing (Stoppin-Mellet et al., 2002), but the targeting of Arabidopsis KATANIN to specific microtubule severing sites (see later) is mediated by 
four different p80 subunits (Wang et al., 2017). Studies in rice showed that the overexpression of a p80 ortholog (OsKTN80a) relates to cell elongation and cell division defects (Wan et al., 2014). In many animal models studied so far, KATANIN activity and localization is also depending on its interactions with TUBULINS and other proteins.

To simplify the text, KATANIN will be used here for the Arabidopsis KATANIN p60. KATANIN deserves a special attention in this review for three reasons. First, ever since its discovery and functional characterization, (McClinton et al., 2001; Stoppin-Mellet et al., 2002) it is a dominant microtubule regulator in plants as evident by studies on various KATANIN mutants with rather severe phenotypes (see later). However, it is worth to note that there are very scarce studies on plant homologs of other microtubule severing AAA-ATPases such as FIDGETIN (Girard et al., 2015) and SPASTIN (Gardiner, 2014) Second, many studies described KATANIN key roles in the organization of cortical microtubule arrays (Stoppin-Mellet et al., 2006; Wightman and Turner, 2007; Nakamura et al., 2010; Lindeboom et al., 2013; Wightman et al., 2013; Zhang et al., 2013; Komis et al., 2017). Third, KATANIN is involved in the regulation of cell division plane orientation (Panteris et al., 2011; Panteris and Adamakis, 2012; Komis et al., 2017) and in the mitotic and cytokinetic progression (Komis et al., 2017).

\section{CHARACTERIZATION OF ARABIDOPSIS KATANIN}

The first plant homolog of animal KATANIN p60 was identified in Arabidopsis thaliana. Since several independent groups studied functions of the Arabidopsis KATANIN p60 simultaneously, the respective gene was identified under diverse names such as BOTERO1 (Bichet et al., 2001), AtKTN1 (Burk et al., 2001), AtKSS (McClinton et al., 2001), Atp60 (Stoppin-Mellet et al., 2002), ECTOPIC ROOT HAIR 3 (ERH3; Webb et al., 2002), FRAGILE FIBER 2 (FRA2, Burk et al., 2001), or LUE1 (Bouquin et al., 2003). KATANIN is composed of 523 amino acid residues with a calculated molecular mass of $57.27 \mathrm{kDa}$. An in vitro ATP-dependent microtubule severing activity was described for recombinant plant KATANIN (Burk and Ye, 2002; StoppinMellet et al., 2002). The Arabidopsis genome contains a single KATANIN p60 and four KATANIN p80 homologs (GenBank accession numbers: AAB71 474, CAC08 339, AAD4 999, and BAB09 559; Bouquin et al., 2003; Keech et al., 2010). All these p80 homologs contain N-terminal WD40 domains, which is involved in the subcellular targeting of KATANIN.

\section{CELLULAR FUNCTIONS OF PLANT KATANIN}

Cellular functions of plant KATANIN have been a matter of intensive research during the past decade. It became apparent that KATANIN is essential to break the initial isotropy of cortical microtubule organization and bias their parallel organization during conditional or developmental establishment of cell growth directionality. KATANIN plays a central role in the coordination of shoot apical meristem growth and emergence of leaf primordia in relation to compressive mechanical forces (Uyttewaal et al., 2012) and auxin signaling (Sassi et al., 2014). It is also involved in blue light- or auxin-induced hypocotyl cell elongation (Lindeboom et al., 2013; Lin et al., 2013).

In this regard, KATANIN was shown to sever emergent, $\gamma$-TUBULIN and AUGMIN-nucleated microtubules, which branch-off from pre-existing microtubules (Nakamura et al., 2010) as well as microtubules that cross each other during their elongation (Wightman and Turner, 2007, 2008; Zhang et al., 2016). Such cross-severing ability of KATANIN is considered to be important for the reorientation of cortical microtubules by blue light or ethylene (Soga et al., 2010a; Lindeboom et al., 2013) since it promotes disassembly of microtubules with unfavorable orientation. A recent modeling study uncovered the possibility that KATANIN-mediated severing at microtubule crossovers should only occur under permissive angles of encounter, below which microtubule bundling is more likely (Deinum et al., 2017). Moreover, KATANIN activity might support microtubule bundling (Stoppin-Mellet et al., 2006). There are also other microtubule binding proteins, e.g., TORTIFOLIA1 (SPIRAL2), which can regulate KATANIN severing activity (Buschmann et al., 2004; Wightman et al., 2013).

\section{THE ROLE OF KATANIN IN PLANT MITOSIS AND CELL DIVISION PLANE ORIENTATION}

Some studies proposed the role of KATANIN in microtubule organization within preprophase band (PPB; Panteris et al., 2011; Komis et al., 2017) but showed conflicting results regarding the role of KATANIN in mitotic spindle formation. In this respect fra2, lue1, bot1, and ktn1-2 mutants possessed pronounced multipolar prophase spindles (Panteris et al., 2011; Panteris and Adamakis, 2012), although a previous study using tubulin immunolabeling failed to show spindle defects in fra2 mutant (Burk et al., 2001). The latter results were recently corroborated with live cell imaging of dividing ktn 1-2 cells which showed normal spindle formation but marked delay in mitotic progression and deregulation of spindle positioning throughout mitosis (Komis et al., 2017). Microtubule organization of the phragmoplast was also affected (Panteris et al., 2011; Komis et al., 2017), while its centrifugal expansion was delayed (Komis et al., 2017). In the context of cell division plane orientation some studies showed disorganized cell files in roots of various KATANIN mutants (Bichet et al., 2001; Webb et al., 2002; Panteris et al., 2011). Although it was suggested that spindle multipolarity in KATANIN mutants might define the plane of phragmoplast expansion (Panteris et al., 2011), it was later shown that it rather followed the plane of the aberrant PPB (Komis et al., 2017). The connection of $\mathrm{PPB}$ to cell division plane orientation was very recently revisited revealing that $\mathrm{PPB}$ is involved in mitotic spindle positioning (Schaefer et al., 2017). In this respect, our work on the ktn1-2 mutant showed aberrant PPB formation and uncontrolled spindle rotational motions during cell division (Komis et al., 2017). Although these results are preliminary, they suggest a 
role of KATANIN in spindle-cell cortex interactions which are co-aligning the spindle equator with the PPB-determined cell division zone (Smertenko et al., 2017) and define the geometry of cell plate expansion later during cytokinesis.

On the other hand, spindle assembly was not visibly affected and it is a pending question whether the localization of KATANIN in Arabidopsis mitotic spindles (Panteris et al., 2011) regulates spindle formation and shape or spindle sizing as it was previously reported (McNally et al., 2006; Loughlin et al., 2011; Panteris et al., 2011).

\section{IDENTIFICATION OF DEVELOPMENTAL ROLES OF KATANIN USING MUTANTS}

There have been many KATANIN mutants identified during the past years and for many of them information on the nature of the mutation is missing (Table 1). Some mutants are predicted to lack KATANIN or encode truncated versions while others presumably affect some particular protein domain (e.g., the AAAATPase domain as in the case of erh3 alleles; Table 1) but with unknown consequences for the functionality of the protein produced. On the other hand, the inducible overexpression of KATANIN was shown to cause heavy fragmentation of cortical microtubules while favoring microtubule bundling in Arabidopsis pavement cells (Stoppin-Mellet et al., 2006). Table 1 also provides comparative information related to phenotypes of diverse KATANIN mutants.

The first described Arabidopsis mutant of KATANIN in the locus named BOTERO1 (BOT1) was bot1-1. It is an EMS (ethyl methane sulfonate) mutant in the genetic background of Col-0 ecotype. Seven alleles have been described in this locus: bot1-1 to bot1-5, bot1-7, and bot1-8 (Tables 1, 2; Bichet et al., 2001). These mutants exhibit radially swollen cells with isotropic cortical microtubule arrays, suggesting a specific role of BOT1 in the organization of cortical microtubules during cell elongation. Thus, botero1 mutant has round and thick leaves and thick stems. Hypocotyls are shorter and thicker, inflorescence stems have shorter internodes and shorter anthers might cause reduced fertility. Cortical microtubules of leaf primordia show delayed reorientation responses during mechanical stimulation (Uyttewaal et al., 2012). However, the mutation has no effect on tip growth of root hairs and pollen tubes, and on trichome morphogenesis (Bichet et al., 2001). During mitosis, PPB microtubules in bot 1 root cells exhibit malorganized and defective perinuclear formation while the cytokinetic phragmoplast shows aberrant microtubule organization (Panteris and Adamakis, 2012).

The mutant fragile fiber 2 (fra2) is an EMS mutant (Tables 1,2) which displays fragility of all organs and particularly of stems. This fragility is accompanied by reduced cellulose deposition, resulting in shorter and thinner fibers and increased fragility due to the lower mechanical resistance. Cell growth is aberrant in all organs of such mutant with pleiotropic phenotypes. As reported trichome morphogenesis is affected (Burk et al., 2001) unlike to what was observed for botero mutants (Bichet et al., 2001). The mutant displays dwarf phenotype
(Figure 1). The size of inflorescence stem is strongly reduced and it is related to the decreased length of internodes, but not to their lower number. Rosette leaves are more round-shaped and have smaller blades. Sepals, petals, pistils, anthers, and siliques are shorter and thicker. Siliques bear unfertilized ovules and seed set is reduced. Ovule development is variably defective ranging from normal to severely malformed, suggesting an abnormal migration and positioning of nuclei and problematic polar nuclei fusion (Burk et al., 2001; Luptovciak et al., 2017). Most trichomes on fra2 leaves have two instead of three branches (Burk et al., 2001).

Luo and Oppenheimer (1999) have identified mutants that show a reduction in trichome branch number from three branches to two and they named them furca (two-pronged fork in the Latin). One of these genes called FURCA2 (FRC2) was later replaced in TAIR database as BOT1 and ERH3. There are three frc2 alleles: $f r c 2-1, f r c 2-2, f r c 2-3$, and about $60 \%$ of their trichomes show two branches. frc2-1 and frc2-3 have apparently decreased fertility compared to the wild-type plants which is caused by a premature extension of the pistil from the unopened flower before anthers mature.

Another set of EMS mutants is designated as ectopic root hair 3 (erh 3-1 to erh 1-3; Tables 1, 2) as they display disturbed root and root hair phenotypes. In this case, the authors studied root hair emergence and the developmental succession of trichoblasts and atrichoblasts in the root epidermis, rather than the process of root hair tip growth. All three erh3 mutants have point mutations in the AAA-ATPase domain, however, it is not clear whether this can influence nucleotide occupancy and subsequently KATANIN oligomerization and severing. The most severe phenotypical defects have been observed in the erh3-2 mutant where the root is the shortest compared to the wild type and appears radially swollen while root tissue patterning is disturbed (Webb et al., 2002).

The lue 1 mutation was originally isolated in the screening of mutants with altered expression of GA20-oxidase, and the gene was named LUCIFERASE SUPER-EXPRESSOR1 (LUE1; Tables 1, 2). It is a recessive mutation displaying dwarf mutant phenotype achieving only $30 \%$ of the wild type size (Meier et al., 2001; Bouquin et al., 2003) (Figure 1). Cortical microtubules and cellulose microfibrils are abnormally arranged in the lue 1 mutant. In comparison to the wild type, lue 1 mutant has shorter leaves and inflorescences, while siliques contain $80 \%$ less seeds being bigger and more round (Luptovciak et al., 2017). This mutant also shows altered ethylene sensitivity leading to the improper formation of the hypocotyl hook and to decreased hypocotyl elongation (Bouquin et al., 2003).

Next, there are five KATANIN 1 mutants named $k t n 1-1$ to $k t n 1-5$ with $k t n 1-2$ and ktn1-5 being T-DNA null mutants, and $k t n 1-1, k t n 1-3$, and $k t n 1-4$ being point mutants (Tables 1, 2; Nakamura et al., 2010; Lin et al., 2013). The ktn1-2 mutant displays dwarf phenotype (Figure 1). Fertility is reduced in the null ktn1-2 mutant, while aberrant orientations of cell divisions and abnormal formation of hypophysis affect embryogenesis (Luptovciak et al., 2017). In addition, many developmental phenotypes of $k t n$ mutants are consistent with described phenotypes of other KATANIN mutants. For example, ktn1-2 
TABLE 1 | Genetic characteristics of Arabidopsis KATANIN mutants and in silico prediction of modifications in amino acid sequences.

\begin{tabular}{|c|c|c|c|c|c|c|c|c|c|}
\hline Allele & Ecotype & Mutagen & $\begin{array}{l}\text { Genomic } \\
\text { sequence }\end{array}$ & $\begin{array}{l}\text { Coding DNA } \\
\text { sequence }\end{array}$ & Exon & $\begin{array}{l}\text { Codon } \\
\text { modification }\end{array}$ & $\begin{array}{l}\text { Amino acid } \\
\text { modification }\end{array}$ & Position in domain & References \\
\hline bot1-1 & Col-0 & EMS & n.a. & n.a. & n.a. & n.a. & n.a. & n.a. & Bichet et al., 2001 \\
\hline bot1-3 & Col-0 & EMS & n.a. & n.a. & n.a. & n.a. & n.a. & n.a. & Bichet et al., 2001 \\
\hline bot1-4 & Col-0 & EMS & n.a. & n.a. & n.a. & n.a. & n.a. & n.a. & Bichet et al., 2001 \\
\hline bot1-7 & Ws & T-DNA & $\begin{array}{l}32-50 \mathrm{bp} \\
\text { del }\end{array}$ & 32-50 bp del & 1. exon & TTA-TAG & L17-stop & $\begin{array}{l}\text { p80 interacting } \\
\text { domain }\end{array}$ & $\begin{array}{l}\text { Bichet et al., 2001; } \\
\text { Uyttewaal et al., } 2012\end{array}$ \\
\hline bot1-8 & Ws & T-DNA & n.a. & n.a. & n.a. & n.a. & n.a. & n.a. & Bichet et al., 2001 \\
\hline erh3-1 & Col-0 & EMS & C1863T & C1057T & 5. exon & CAT-TAT & H353Y & AAA domain & $\begin{array}{l}\text { Schneider et al., 1997; } \\
\text { Webb et al., } 2002\end{array}$ \\
\hline erh3-2 & Col-0 & EMS & G1551A & G820A & 4. exon & GGA-AGA & G274R & $\begin{array}{l}\text { AAA domain, close } \\
\text { to Walker A }\end{array}$ & Webb et al., 2002 \\
\hline frc2-1 & Col-0 & EMS & n.a. & n.a. & n.a. & n.a. & n.a. & n.a. & $\begin{array}{l}\text { Luo and Oppenheimer, } \\
1999\end{array}$ \\
\hline frc2-2 & Col-0 & EMS & n.a. & n.a. & n.a. & n.a. & n.a. & n.a. & $\begin{array}{l}\text { Luo and Oppenheimer, } \\
1999\end{array}$ \\
\hline frc2-3 & RLD & $\begin{array}{l}\text { Fast } \\
\text { neutrons }\end{array}$ & n.a. & n.a. & n.a. & n.a. & n.a. & n.a. & $\begin{array}{l}\text { Luo and Oppenheimer, } \\
1999\end{array}$ \\
\hline$k \operatorname{tn} 1-1$ & n.a. & n.a. & $1584 \mathrm{~A}$ ins & $854 \mathrm{~A}$ ins & 4. exon & GAG-TGA & E295-stop & $\begin{array}{l}\text { AAA domain is } \\
\text { missing }\end{array}$ & Nakamura et al., 2010 \\
\hline$k \operatorname{tn} 1-2$ & Col-0 & T-DNA & n.a. & n.a. & 5. exon & n.a. & n.a. & AAA domain & Nakamura et al., 2010 \\
\hline$k \operatorname{tn} 1-3$ & Col-0 & EMS & C1335T & C773T & 3. exon & ССT-CTT & P258L & rfcL domain & Lin et al., 2013 \\
\hline$k \operatorname{tn} 1-4$ & n.a. & EMS & C2359T & C1379T & 7. exon & TCA-TTA & S460L & $\begin{array}{l}\text { between AAA and } \\
\text { Vps domains }\end{array}$ & Lin et al., 2013 \\
\hline
\end{tabular}

del, deletion; ins, insertion; EMS, ethyl methanesulfonate; Tnt1, retrotransposon Tht1 mediated mutation. n.a., data not available; Domain characterization of AtKTN1 was predicted based on sequence homology with human katanin (Gosh et al., 2012).

mutant shows defective organization of mitotic microtubule arrays, delay in mitotic progression and orientation defects of these arrays during cytokinesis (Panteris and Adamakis, 2012; Komis et al., 2017). Moreover, cortical microtubule organization and dynamics were also shown to be affected in the hypocotyl, petiole (Figure 2) and leaf epidermal cells (Lindeboom et al., 2013; Zhang et al., 2013; Komis et al., 2017).

The homolog of KATANIN in rice (Oryza sativa) is named DWARF AND GLADIUS LEAF 1 (DGL1; Table 2). Three mutants, named $d g l 1-1, d g l 1-2$, and $d g l 1-3$ were identified and display similar traits like dwarfism, differentially disturbed floral organ development and leaf blade morphology with shorter and more round leaves. These mutants show minimal response to gibberellins and brassinosteroids, two hormones regulating the stem height (Komorisono et al., 2005).

A decade ago, Nagawa et al. (2006) created the KG12419 gene trap line with disrupted KATANIN gene and showing GUS staining under the control of KTN promoter. This line exhibited a high GUS activity in the procambium cells (elongated precursors of vascular cells) of various organs. These authors observed a significant shortening of procambium cells of higher order vein in young leaves as well as aberrant trichomes and defective root hair formation in the homozygous KG12419 line.

\section{PHYSIOLOGICAL FUNCTIONS OF KATANIN}

Studies on KATANIN mutants revealed that the altered microtubule severing has also a number of physiological consequences. First of all, KATANIN is a microtubule-interacting protein which can connect the external environment with microtubule regulation (Nakamura, 2015). The sensitivity of KATANIN to external stimuli is likely mediated by Rho GTPase signaling (Lin et al., 2013), however, other mechanisms cannot 


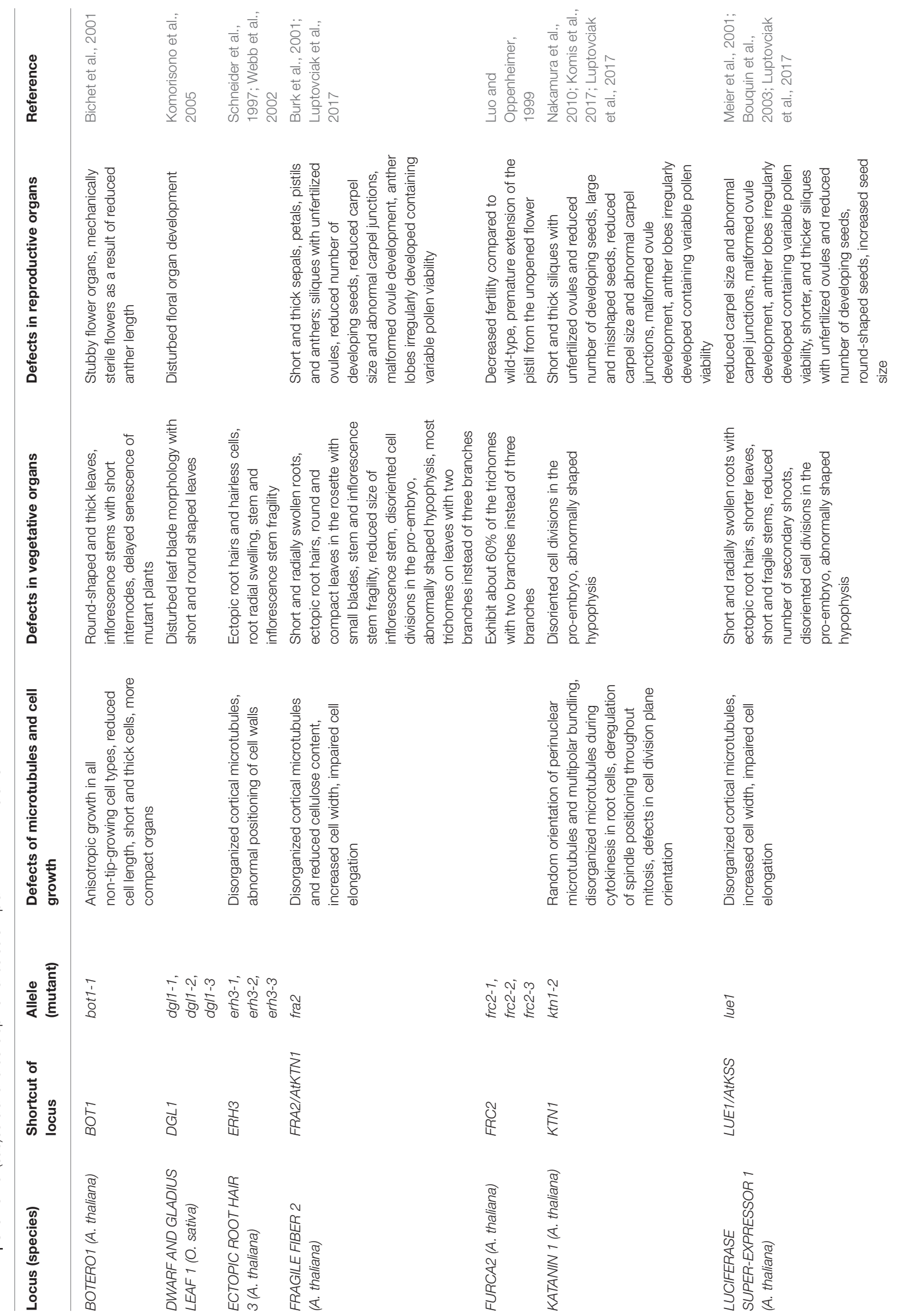




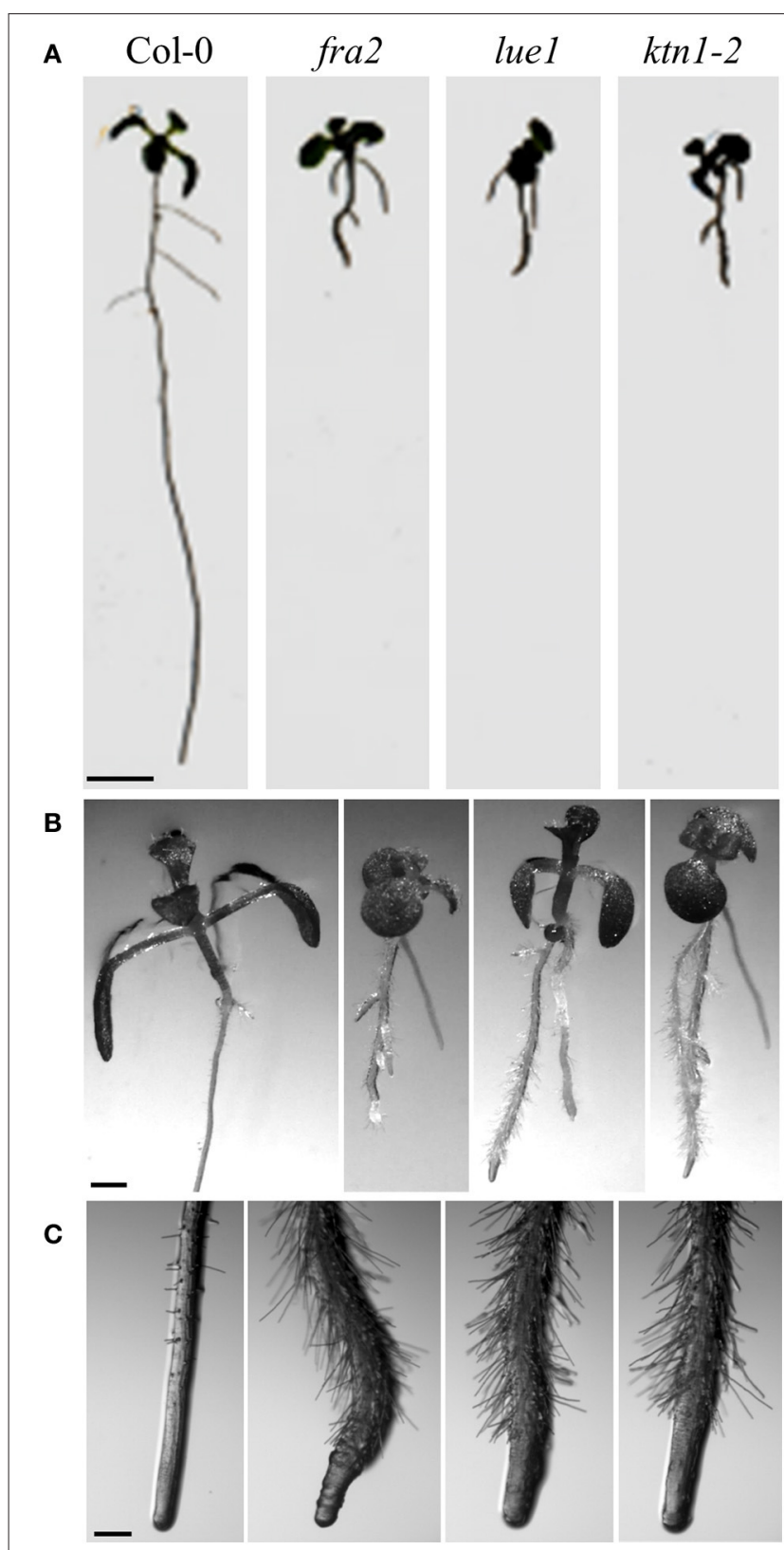

FIGURE 1 | Morphological phenotypes of KATANIN mutants vs. Col-0 wild-type (7 days old seedlings). (A) Representative pictures of whole Col-0 seedlings and KATANIN mutants. Note much shorter roots in the mutants. (B) Detailed pictures of above ground seedling parts in Col-0 and KATANIN mutants. (C) Detailed pictures of primary root tips of Col-0 and KATANIN mutants. Note radial expansion of mutant roots. Scale bars $=5 \mathrm{~mm}(\mathbf{A}) ; 1 \mathrm{~mm}$ (B); $250 \mu \mathrm{m}$ (C)

be excluded. External stimuli cause reorientation of microtubules followed by specific developmental reprogramming. Such mechanism is linking hormonal regulation to the cytoskeleton, because KATANIN is involved in gibberellic acid (GA) (Meier et al., 2001; Bouquin et al., 2003) ethylene (Soga et al., 2010a,b) and auxin responses (Chen et al., 2014).
Arabidopsis KATANIN mutants show defective microtubule reorientation in response to GA, ethylene and auxin (Bouquin et al., 2003; Komorisono et al., 2005; Soga et al., 2010a; Chen et al., 2014; Sassi et al., 2014). KATANIN transcript accumulation (by an unknown mechanism) is induced by these hormones (Bouquin et al., 2003; Soga et al., 2010a, eFP browser hormone series http://bbc.botany.utoronto.ca/efp). It is therefore supposed to control GA, ethylene, and auxin-dependent developmental processes requiring microtubule reorientation. Impaired responses of KATANIN mutants are likely connected to the altered synthesis and metabolism of hormones. This was demonstrated by increased mRNA levels of GA biosynthetic enzymes in rice mutant $d g l 1$ (Komorisono et al., 2005) and by changed abundances of proteins involved in GA, ethylene, auxin, and abscisic acid metabolism in fra2 and ktn1-2 mutants (Takáč et al., 2017). Thus, KATANIN might be a protein integrating multiple microtubule-dependent hormonal responses. Other proteins involved in hormonal signal integration are DELLA proteins (Achard et al., 2006; Santner and Estelle, 2009). DELLA proteins are suppressed by GA via their destabilization (Fu et al., 2002). Interestingly, DELLA proteins have been found to mediate microtubule reorientation during GA response. The mechanism is based on DELLA interaction with prefoldin complex, which is disrupted by DELLA degradation during GA response. Prefoldin complex is important for tubulin folding ( $\mathrm{Gu}$ et al., 2008). When mislocalized to the nucleus it causes altered microtubule organization (Locascio et al., 2013). It was proposed that apart from tubulin monomer supply, an additional mechanism such as microtubule severing can be implicated in the final organization of microtubule arrays (Locascio et al., 2013). According to these reports, KATANIN might work in concert with DELLA-prefoldin complex. Nevertheless, a molecular interplay between DELLA and KATANIN remains to be confirmed. KATANIN likely is not required for DELLA degradation, since DELLA is destabilized in the rice $d g l 1$ mutant (Komorisono et al., 2005).

In addition to hormonal stimuli, KATANIN mediates the reorientation of cortical microtubules upon blue light exposure (Lindeboom et al., 2013). Under blue light, hypocotyl phototropism was connected to KATANIN severing activity at the microtubule crossovers, resulting in the formation of new microtubules with transversal orientation. KATANIN is regulated by phototropin receptor, as evidenced by cell biological analyses of phot1phot 2 double mutant (Lindeboom et al., 2013). In this context, KATANIN was identified by using yeast two hybrid assay as an interactor of the actin-binding kinesin-like protein KIN-14A (Bouquin et al., 2003; Suetsugu et al., 2012). This is a microtubule motor protein involved in blue light induced chloroplast movements (Suetsugu et al., 2010), where phototropins PHOT1 and PHOT2 play a crucial role (Luesse et al., 2010). Therefore, it is likely that interactions between KATANIN, phototropins and kinesin-like protein KIN-14A govern the blue light induced chloroplast movement. Microtubule severing is also required for plant responses to mechanical forces (Uyttewaal et al., 2012; Sampathkumar et al., 2014). This is essential for the control of cell shape, growth anisotropy and plant morphogenesis. 


\section{A}

Col-0

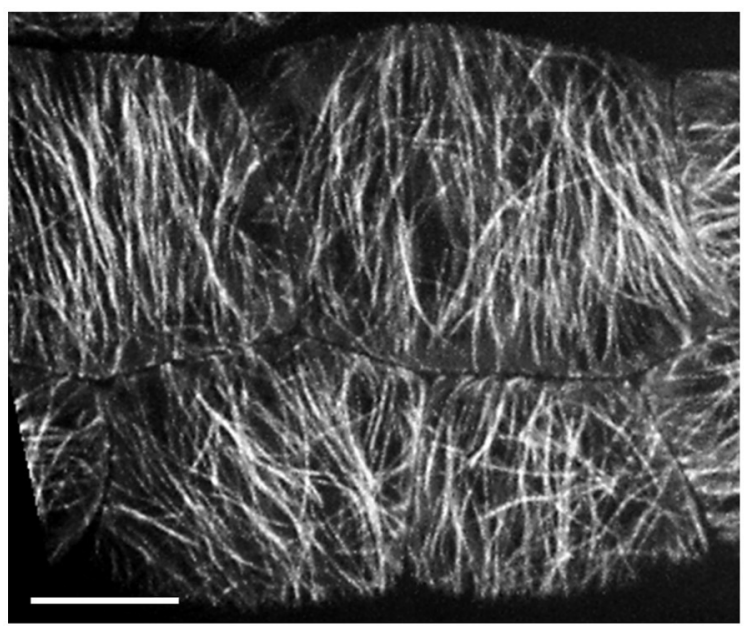

C

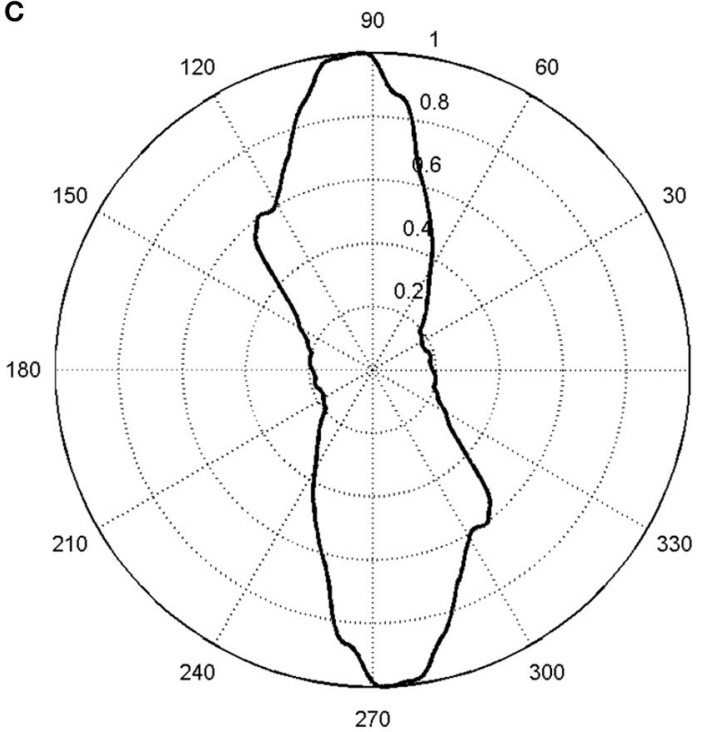

Angle (degrees)
B $\quad k t n 1-2$

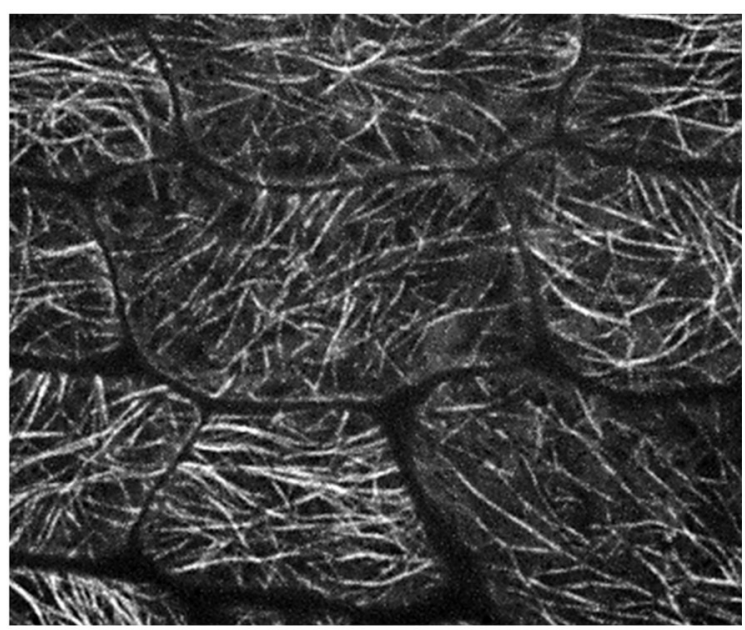

D

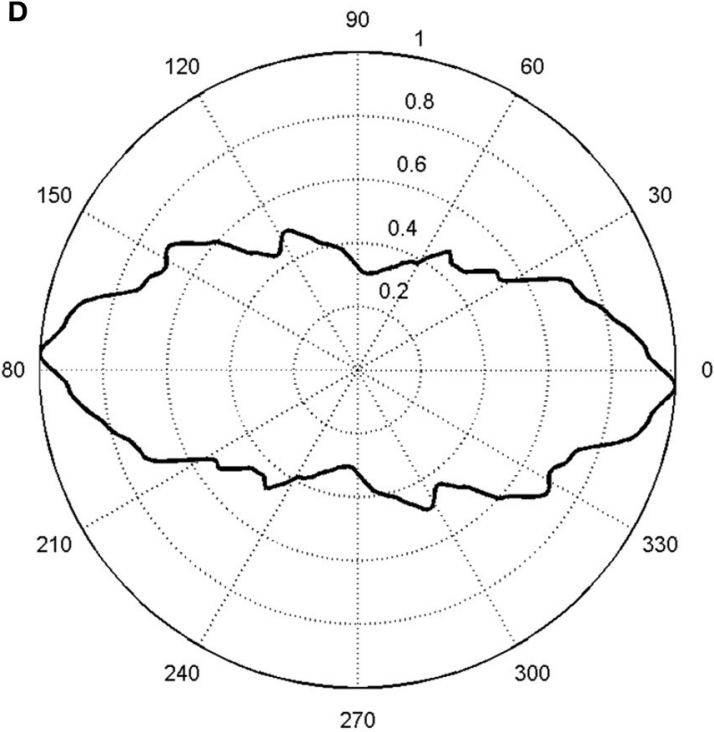

Angle (degrees)

FIGURE 2 | Differences in the microtubule organization and cell shape of Arabidopsis thaliana Col-0 and ktn1-2 petiole epidermal cells carrying a GFP-TUA6 microtubule marker after spinning disk microscopy imaging. In differentiated cells, most cortical microtubules are transversal to the cell axis in Col-0 showing parallel placement to each other (A) resulting in relatively narrow angular distribution (C) whereas they appear more disorganized and randomly oriented in ktn 1-2

(B) exhibiting broader angular distribution pattern (D). Scale bar $=10 \mu \mathrm{m}$.

KATANIN is also important for translational miRNAmediated repression, as revealed by genetic screen (Brodersen et al., 2008). The Arabidopsis mutant mad5, carrying G-to-A transition in the start codon of KATANIN, showed increased abundances of miRNA-targeted proteins. Similar results were obtained in fra2 and lue1 mutants, whose genetic background differs from that of mad5 (Table 1). Defects in miRNAmediated translational repression might suggest that some overabundant proteins in fra 2 and lue 1 mutants found in a recent proteomic study (Takáč et al., 2017) belong to miRNA-targeted proteins. Notably, fra 2 and lue1 mutants also showed substantial alterations in the translational machinery, represented by changes in the abundance of ribosomal proteins (Takáč et al., 2017). The mRNA silencing machinery is closely connected to stress granules (Mollet et al., 2008). Stress granules are assembled during environmental stress and are sites of post-transcriptional mRNA processing and silencing (Anderson and Kedersha, 2008). KATANIN is implicated in stress granule formation (GutierrezBeltran et al., 2015) and mediates the abundance and the accumulation of Tudor staphylococcal nuclease proteins (TSN1 and 2) (Takáč et al., 2017). These proteins are important for stress-induced mRNA decapping in the stress granules and they modulate abiotic stress responses (Gutierrez-Beltran et al., 2015). 


\section{FUTURE DIRECTIONS}

In conclusion, microtubule severing by KATANIN appears to be crucial for a broad range of important cellular, developmental, and physiological processes in plants.

Undoubtedly, studies on KATANIN brought about fascinating results on how microtubule severing can lead to the biased organization of cortical microtubules during conditional cell growth. It is fascinating to see that KATANIN provides a molecular connection between extracellular stimulation via physical signals such as light or mechanical forces and coordination of cell growth in a multicellular context. In this respect, it will be of interest to look on the microtubule counterpart and understand the features of the microtubule lattice at branching or crossover sites that are attracting KATANIN. Maybe these sites accumulate lattice defects (Davis et al., 2002; Díaz-Valencia et al., 2011; Jiang et al., 2017) or tubulin post-translational modifications which may target or regulate KATANIN activity similarly to SPASTIN (Lacroix et al., 2010; Sudo and Baas, 2010; Valenstein and RollMecak, 2016). The field of plant KATANIN research is largely devoid of similar functional studies while data on modifiers of KATANIN activity and/or localization are scarce and mostly based on genetic evidence (e.g., Trehin et al., 2013; Wightman et al., 2013; Chen et al., 2014; Sassi et al., 2014). Therefore, KATANIN mutants should be better characterized regarding their biochemical and cell biological properties.

On the other hand, KATANIN function during mitotic cell division is still obscure and we believe that a very promising

\section{REFERENCES}

Achard, P., Cheng, H., De Grauwe, L., Decat, J., Schoutteten, H., Moritz, T., et al. (2006). Integration of plant responses to environmentally activated phytohormonal signals. Science 311, 91-94. doi: 10.1126/science.1118642

Anderson, P., and Kedersha, N. (2008). Stress granules: the Tao of RNA triage. Trends Biochem. Sci. 33, 141-150. doi: 10.1016/j.tibs.2007.12.003

Bailey, M. E., Sackett, D. L., and Ross, J. L. (2015). Katanin severing and binding microtubules are inhibited by tubulin carboxy tails. Biophys. J. 109, 2546-2561. doi: 10.1016/j.bpj.2015.11.011

Bichet, A., Desnos, T., Turner, S., Grandjean, O., and Höfte, H. (2001). BOTERO1 is required for normal orientation of cortical microtubules and anisotropic cell expansion in Arabidopsis. Plant J. 25, 137-148. doi: 10.1046/j.1365-313x.2001.00946.x

Bouquin, T., Mattsson, O., Naested, H., Foster, R., and Mundy, J. (2003). The Arabidopsis lue 1 mutant defines a katanin p60 ortholog involved in hormonal control of microtubule orientation during cell growth. J. Cell. Sci. 116, 791-801. doi: $10.1242 /$ jcs. 00274

Brodersen, P., Sakvarelidze-Achard, L., Bruun-Rasmussen, M., Dunoyer, P., Yamamoto, Y. Y., Sieburth, L., et al. (2008). Widespread translational inhibition by plant miRNAs and siRNAs. Science 320, 1185-1190. doi: 10.1126/science.1159151

Burk, D. H., Liu, B., Zhong, R., Morrison, W. H., and Ye, Z. H. (2001). A kataninlike protein regulates normal cell wall biosynthesis and cell elongation. Plant Cell 13, 807-827. doi: 10.1105/tpc.13.4.807

Burk, D. H., and Ye, Z.-H. (2002). Alteration of oriented deposition of cellulose microfibrils by mutation of a katanin-like microtubule-severing protein. Plant Cell 14, 2145-2160. doi: 10.1105/tpc.003947 future direction will be to address in more detail the roles of microtubule severing in the PPB formation and maturation, in the mitotic spindle assembly and in the positioning and guidance of the phragmoplast. It is of particular interest to see how KATANIN is distributed within the PPB and how microtubule severing is coordinated during $\mathrm{PPB}$ narrowing since $\mathrm{PPB}$ maturation is significantly prolonged and frequently disturbed in KATANIN mutants (Panteris et al., 2011; Komis et al., 2017). It will be also necessary to decipher whether KATANIN is necessary (Panteris et al., 2011) or not (Komis et al., 2017) for mitotic spindle assembly and see whether KATANIN activity may be linked to spindle scaling issues as it does in animals (McNally et al., 2006; Loughlin et al., 2011). Finally, the role of KATANIN in the establishment of spindle-cell cortex association necessary for spindle positioning is another pending question.

Last but not least, is the necessity to characterize the importance of plant FIDGETIN and SPASTIN homologs in order to acquire a full view on the roles of microtubule severing proteins during plant growth and development.

\section{AUTHOR CONTRIBUTIONS}

All authors listed have made a substantial, direct and intellectual contribution to the work, and approved it for publication.

\section{ACKNOWLEDGMENTS}

This research was supported by Grant No. 15-19284S from the Czech Science Foundation GACR.
Buschmann, H., Fabri, C. O., Hauptmann, M., Hutzler, P., Laux, T., Lloyd, C. W., et al. (2004). Helical growth of the Arabidopsis mutant tortifolial reveals a plant-specific microtubule-associated protein. Curr. Biol. 14, 1515-1521. doi: 10.1016/j.cub.2004.08.033

Chen, X., Grandont, L., Li, H., Hauschild, R., Paque, S., Abuzeineh, A., et al. (2014). Inhibition of cell expansion by rapid ABP1-mediated auxin effect on microtubules. Nature 516, 90-93. doi: 10.1038/nature13889

Davis, L. J., Odde, D. J., Block, S. M., and Gross, S. P. (2002). The importance of lattice defects in katanin-mediated microtubule severing in vitro. Biophys. J. 82, 2916-2927. doi: 10.1016/S0006-3495(02)75632-4

Deinum, E. E., Tindemans, S. H., Lindeboom, J. J., and Mulder, B. M. (2017). How selective severing by katanin promotes order in the plant cortical microtubule array. Proc. Natl. Acad. Sci. U.S.A. 114, 6942-6947. doi: 10.1073/pnas.1702650114

Díaz-Valencia, J. D., Morelli, M. M., Bailey, M., Zhang, D., Sharp, D. J., and Ross, J. L. (2011). Drosophila katanin-60 depolymerizes and severs at microtubule defects. Biophys. J. 100, 2440-2449. doi: 10.1016/j.bpj.2011.03.062

Eckert, T., Le, D. T., Link, S., Friedmann, L., and Woehlke, G. (2012). Spastin's microtubule-binding properties and comparison to katanin. PLoS ONE 7:e50161. doi: 10.1371/journal.pone.0050161

Fu, X., Richards, D. E., Ait-Ali, T., Hynes, L. W., Ougham, H., Peng, J., et al. (2002). Gibberellin-mediated proteasome-dependent degradation of the barley DELLA protein SLN1 repressor. Plant Cell 14, 3191-3200. doi: 10.1105/tpc.006197

Gardiner, J. (2014). “Movement disorders, 2nd Edn," in Use of Arabidopsis to Model Hereditary Spastic Paraplegia and Other Movement Disorders, ed M. LeDoux (Amsterdam: Elsevier Publishers), 1136-1142.

Girard, C., Chelysheva, L., Choinard, S., Froger, N., Macaisne, N., Lemhemdi, A., et al. (2015). AAA-ATPase FIDGETIN-LIKE 1 and Helicase FANCM 
antagonize meiotic crossovers by distinct mechanisms. PLoS Genet. 11:e1005369. doi: 10.1371/journal.pgen.1005369

Gosh, D., Dasgupta, D., and Guha, A. (2012). Models, regulations, and functions of microtubule severing by katanin. ISRN Mol. Biol. 2012:596289. doi: 10.5402/2012/596289

Gu, Y., Deng, Z., Paredez, A. R., DeBolt, S., Wang, Z. Y., and Somerville, C. (2008). Prefoldin 6 is required for normal microtubule dynamics and organization in Arabidopsis. Proc. Natl. Acad. Sci. U.S.A. 105, 18064-18069. doi: $10.1073 /$ pnas.0808652105

Gutierrez-Beltran, E., Moschou, P. N., Smertenko, A. P., and Bozhkov, P. V. (2015). Tudor staphylococcal nuclease links formation of stress granules and processing bodies with mRNA catabolism in Arabidopsis. Plant Cell 27, 926-943. doi: 10.1105/tpc.114.134494

Hartman, J. J., Mahr, J., McNally, K., Okawa, K., Iwamatsu, A., Thomas, S., et al. (1998). Katanin, a microtubule-severing protein, is a novel AAA ATPase that targets to the centrosome using a WD40-containing subunit. Cell 93, 277-287. doi: 10.1016/S0092-8674(00)81578-0

Hartman, J. J., and Vale, R. D. (1999). Microtubule disassembly by ATPdependent oligomerization of the AAA enzyme katanin. Science 286, 782-785. doi: 10.1126/science.286.5440.782

Jiang, K., Rezabkova, L., Hua, S., Liu, Q., Capitani, G., Maarten, A. F., et al. (2017). Microtubule minus-end regulation at spindle poles by an ASPM-katanin complex. Nat. Cell Biol. 19, 480-492. doi: 10.1038/ncb3511

Keech, O., Pesquet, E., Gutierrez, L., Ahad, A., Bellini, C., Smith, S. M., et al. (2010). Leaf senescence is accompanied by an early disruption of the microtubule network in Arabidopsis. Plant Physiol. 154, 1710-1720. doi: $10.1104 /$ pp.110.163402

Komis, G., Luptovčiak, I., Ovečka, M., Samakovli, D., Šamajová, O., and Šamaj, J. (2017). Katanin effects on dynamics of cortical microtubules and mitotic arrays in Arabidopsis thaliana revealed by advanced live-cell imaging. Front. Plant Sci. 8:866. doi: 10.3389/fpls.2017.00866

Komorisono, M., Ueguchi-Tanaka, M., Aichi, I., Hasegawa, Y., Ashikari, M., Kitano, H., et al. (2005). Analysis of the rice mutant dwarf and gladius leaf 1 . Aberrant katanin-mediated microtubule organization causes up-regulation of gibberellin biosynthetic genes independently of gibberellin signaling. Plant Physiol. 138, 1982-1993. doi: 10.1104/pp.105. 062968

Lacroix, B., van Dijk, J., Gold, N. D., Guizetti, J., Aldrian-Herrada, G., Rogowski, K., et al. (2010). Tubulin polyglutamylation stimulates spastinmediated microtubule severing. J. Cell Biol. 189, 945-954. doi: 10.1083/jcb.2010 01024

Lin, D., Cao, L., Zhou, Z., Zhu, L., Ehrhardt, D., Yang, Z., et al. (2013). Rho GTPase signaling activates microtubule severing to promote microtubule ordering in Arabidopsis. Curr. Biol. 23, 290-297. doi: 10.1016/j.cub.2013.01.022

Lindeboom, J. J., Nakamura, M., Hibbel, A., Shundyak, K., Gutierrez, R., Ketelaar, T., et al. (2013). A mechanism for reorientation of cortical microtubule arrays driven by microtubule severing. Science 342:1245533. doi: 10.1126/science.1245533

Locascio, A., Blázquez, M. A., and Alabadí, D. (2013). Dynamic regulation of cortical microtubule organization through prefoldin-DELLA interaction. Curr. Biol. 23, 804-809. doi: 10.1016/j.cub.2013.03.053

Loughlin, R., Wilbur, J. D., McNally, F. J., Nédélecm, F. J., and Heald, R. (2011). Katanin contributes to interspecies spindle length scaling in Xenopus. Cell 147, 1397-1407. doi: 10.1016/j.cell.2011.11.014

Lucas, H., Feuerbach, F., Kunert, K., Grandbastien, M.-A., and Caboche, M. (1995). RNA-mediated transposition of the tobacco retrotransposon Tnt1 in Arabidopsis thaliana. EMBO J. 14, 2364-2373.

Luesse, D. R., DeBlasio, S. L., and Hangarter, R. P. (2010). Integration of Phot1, Phot2, and PhyB signalling in light-induced chloroplast movements. J. Exp. Bot. 61, 4387-4397. doi: 10.1093/jxb/erq242

Luo, D., and Oppenheimer, D. G. (1999). Genetic control of trichome branch number in Arabidopsis: the roles of the FURCA loci. Development 126, 5547-5557.

Luptovciak, I., Samakovli, D., Komis, G., and Šamaj, J. (2017). KATANIN 1 is essential for embryogenesis and seed formation in Arabidopsis. Front. Plant Sci. 8:728. doi: 10.3389/fpls.2017.00728

McClinton, R. S., Chandler, J. S., and Callis, J. (2001). cDNA isolation, characterization, and protein intracellular localization of a katanin-like p60 subunit from Arabidopsis thaliana. Protoplasma 216, 181-190. doi: $10.1007 / \mathrm{BF} 02673870$

McNally, F. J., and Vale, R. D. (1993). Identification of katanin, an ATPase that severs and disassembles stable microtubules. Cell 75, 419-429. doi: 10.1016/0092-8674(93)90377-3

McNally, K., Audhya, A., Oegema, K., and McNally, F. J. (2006). Katanin controls mitotic and meiotic spindle length. J. Cell Biol. 175, 881-891. doi: $10.1083 /$ jcb.200608117

McNally, K. P., Bazirgan, O. A., and McNally, F. J. (2000). Two domains of p80 katanin regulate microtubule severing and spindle pole targeting by p60 katanin. J. Cell. Sci. 113(Pt 9), 1623-1633.

Meier, C., Bouquin, T., Nielsen, M. E., Raventos, D., Mattsson, O., Rocher, A., et al. (2001). Gibberellin response mutants identified by luciferase imaging. Plant J. 25, 509-519. doi: 10.1046/j.1365-313x.2001.00980.x

Mollet, S., Cougot, N., Wilczynska, A., Dautry, F., Kress, M., Bertrand, E., et al. (2008). Translationally repressed mRNA transiently cycles through stress granules during Stress. Mol. Biol. Cell 19, 4469-4479. doi: 10.1091/mbc.E08-05-0499

Nagawa, S., Sawa, S., Sato, S., Kato, T., Tabata, S., and Fukuda, H. (2006). Gene trapping in Arabidopsis reveals genes involved in vascular development. Plant Cell Physiol. 47, 1394-1405. doi: 10.1093/pcp/pcl009

Nakamura, M. (2015). Microtubule nucleating and severing enzymes for modifying microtubule array organization and cell morphogenesis in response to environmental cues. New Phytol. 205, 1022-1027. doi: 10.1111/nph.12932

Nakamura, M., Ehrhardt, D. W., and Hashimoto, T. (2010). Microtubule and katanin-dependent dynamics of microtubule nucleation complexes in the acentrosomal Arabidopsis cortical array. Nat. Cell Biol. 12, 1064-1070. doi: $10.1038 /$ ncb2110

Panteris, E., and Adamakis, I. D. (2012). Aberrant microtubule organization in dividing root cells of p60-katanin mutants. Plant Signal. Behav. 7, 16-18. doi: $10.4161 /$ psb.7.1.18358

Panteris, E., Adamakis, I. D., Voulgari, G., and Papadopoulou, G. (2011). A role for katanin in plant cell division: microtubule organization in dividing root cells of fra2 and lue1 Arabidopsis thaliana mutants. Cytoskeleton 68, 401-413. doi: $10.1002 / \mathrm{cm} .20522$

Reed, J. W., Elumalai, R. P., and Chory, J. (1998). Suppressors of an Arabidopsis thaliana phyB mutation identify genes that control light signaling and hypocotyl elongation. Genetics 148, 1295-1310.

Ren, H., Dang, X., Cai, X., Yu, P., Li, Y., Zhang, S., et al. (2017). Spatio-temporal orientation of microtubules controls conical cell shape in Arabidopsis thaliana petals. PLoS Genet. 13:e1006851. doi: 10.1371/journal.pgen.1006851

Sampathkumar, A., Krupinski, P., Wightman, R., Milani, P., Berquand, A., Boudaoud, A., et al. (2014). Subcellular and supracellular mechanical stress prescribes cytoskeleton behavior in Arabidopsis cotyledon pavement cells. Elife 3:e01967. doi: 10.7554/eLife.01967

Santner, A., and Estelle, M. (2009). Recent advances and emerging trends in plant hormone signalling. Nature 459, 1071-1078. doi: 10.1038/nature08122

Sassi, M., Ali, O., Boudon, F., Cloarec, G., Abad, U., Cellier, C., et al. (2014). An auxin-mediated shift toward growth isotropy promotes organ formation at the shoot meristem in Arabidopsis. Curr. Biol. 24, 2335-2342. doi: 10.1016/j.cub.2014.08.036

Schaefer, E., Belcram, K., Uyttewaal, M., Duroc, Y., Goussot, M., Legland, D., et al. (2017). The preprophase band of microtubules controls the robustness of division orientation in plants. Science 356, 186-189. doi: 10.1126/science.aal3016

Schneider, K., Wells, B., Dolan, L., and Roberts, K. (1997). Structural and genetic analysis of epidermal cell differentiation in Arabidopsis primary roots. Development 124, 1789-1798.

Smertenko, A., Assaad, F., Baluška, F., Bezanilla, M., Buschmann, H., Drakakaki, G., et al. (2017). Plant cytokinesis: terminology for structures and processes. Trends Cell Biol. doi: 10.1016/j.tcb.2017.08.008. [Epub ahead of print].

Soga, K., Yamaguchi, A., Kotake, T., Wakabayashi, K., and Hoson, T. (2010a). 1 aminocyclopropane-1-carboxylic acid (ACC)-induced reorientation of cortical microtubules is accompanied by a transient increase in the transcript levels of gamma-tubulin complex and katanin genes in azuki bean epicotyls. J. Plant Physiol. 167, 1165-1171. doi: 10.1016/j.jplph.2010.04.001

Soga, K., Yamaguchi, A., Kotake, T., Wakabayashi, K., and Hoson, T. (2010b). Transient increase in the levels of $\gamma$-tubulin complex and katanin are 
responsible for reorientation by ethylene and hypergravity of cortical microtubules. Plant Signal. Behav. 5, 1480-1482. doi: 10.4161/psb.5.11.13561

Stoppin-Mellet, V., Gaillard, J., Timmers, T., Neumann, E., Conway, J., and Vantard, M. (2007). Arabidopsis katanin binds microtubules using a multimeric microtubule-binding domain. Plant Physiol. Biochem. 45, 867-877. doi: 10.1016/j.plaphy.2007.09.005

Stoppin-Mellet, V., Gaillard, J., and Vantard, M. (2002). Functional evidence for in vitro microtubule severing by the plant katanin homologue. Biochem. J. 365, 337-342. doi: 10.1042/bj20020689

Stoppin-Mellet, V., Gaillard, J., and Vantard, M. (2006). Katanin's severing activity favours bundling of cortical microtubules in plants. Plant J. 46, 1009-1017. doi: 10.1111/j.1365-313X.2006.02761.x

Sudo, H., and Baas, P. W. (2010). Acetylation of microtubules influences their sensitivity to severing by katanin in neurons and fibroblasts. J. Neurosci. 30, 7215-7226. doi: 10.1523/JNEUROSCI.0048-10.2010

Suetsugu, N., Sato, Y., Tsuboi, H., Kasahara, M., Imaizumi, T., Kagawa, T., et al. (2012). The KAC family of kinesin-like proteins is essential for the association of chloroplasts with the plasma membrane in land plants. Plant Cell Physiol. 53, 1854-1865. doi: 10.1093/pcp/pcs133

Suetsugu, N., Yamada, N., Kagawa, T., Yonekura, H., Uyeda, T. Q., Kadota, A., et al. (2010). Two kinesin-like proteins mediate actin-based chloroplast movement in Arabidopsis thaliana. Proc. Natl. Acad. Sci. U.S.A. 107, 8860-8865. doi: 10.1073/pnas.0912773107

Takáč, T., Šamajová, O., Pechan, T., Luptovčiak, I., and Šamaj, J. (2017). Feedback microtubule control and microtubule-actin cross-talk in Arabidopsis revealed by integrative proteomic and cell biology analysis of KATANIN 1 mutants. Mol. Cell Proteomics 16, 1591-1609. doi: 10.1074/mcp.M117.068015

Trehin, C., Schrempp, S., Chauvet, A., Berne-Dedieu, A., Thierry, A. M., Faure, et al. (2013). QUIRKY interacts with STRUBBELIG and PAL OF QUIRKY to regulate cell growth anisotropy during Arabidopsis gynoecium development. Development 140, 4807-4817. doi: 10.1242/dev.091868

Uyttewaal, M., Burian, A., Alim, K., Landrein, B., Borowska-Wykret, D., Dedieu, A., et al. (2012). Mechanical stress acts via katanin to amplify differences in growth rate between adjacent cells in Arabidopsis. Cell 149, 439-451. doi: 10.1016/j.cell.2012.02.048

Valenstein, M. L., and Roll-Mecak, A. (2016). Graded control of microtubule severing by tubulin glutamylation. Cell 164, 911-921. doi: 10.1016/j.cell.2016.01.019

Wan, L., Wang, X., Li, S., Hu, J., Huang, W., and Zhu, Y. (2014). Overexpression of OsKTN80a, a katanin P80 ortholog, caused the repressed cell elongation and stalled cell division mediated by microtubule apparatus defects in primary root in Oryza sativa. J. Integr. Plant Biol. 56, 622-634. doi: 10.1111/jipb.12170

Wang, C., Liu, W., Wang, G., Li, J., Dong, L., Han, L., et al. (2017). KTN80 confers precision to microtubule severing by specific targeting of katanin complexes in plant cells. EMBO J. doi: 10.15252/embj.201796823. [Epub ahead of print].

Webb, M., Jouannic, S., Foreman, J., Linstead, P., and Dolan, L. (2002). Cell specification in the Arabidopsis root epidermis requires the activity of ECTOPIC ROOT HAIR 3-a katanin-p60 protein. Development 129, 123-131.

Wightman, R., Chomicki, G., Kumar, M., Carr, P., and Turner, S. R. (2013). SPIRAL2 determines plant microtubule organization by modulating microtubule severing. Curr. Biol. 23, 1902-1907. doi: 10.1016/j.cub.2013.07.061

Wightman, R., and Turner, S. R. (2007). Severing at sites of microtubule crossover contributes to microtubule alignment in cortical arrays. Plant J. 52, 742-751. doi: 10.1111/j.1365-313X.2007.03271.x

Wightman, R., and Turner, S. R. (2008). A novel mechanism important for the alignment of microtubules. Plant Signal. Behav. 3, 238-239. doi: $10.4161 /$ psb.3.4.5140

Zehr, E., Szyk, A., Piszczek, G., Szczesna, E., Zuo, X., and Roll-Mecak, A. (2017). Katanin spiral and ring structures shed light on power stroke for microtubule severing. Nat. Struct. Mol. Biol. 24, 717-725. doi: 10.1038/nsmb. 3448

Zhang, Q., Fischel, E., Bertoche, T., and Dixit, R. (2013). Microtubule severing at crossover sites by katanin generates order cortical microtubular arrays in arabidopsis. Curr. Biol. 23, 2191-2195. doi: 10.1016/j.cub.2013. 09.018

Zhang, Y., Iakovidis, M., and Costa, S. (2016). Control of patterns of symmetric cell division in the epidermal and cortical tissues of the Arabidopsis root. Development 143, 978-982. doi: 10.1242/dev.129502

Conflict of Interest Statement: The authors declare that the research was conducted in the absence of any commercial or financial relationships that could be construed as a potential conflict of interest.

Copyright (C) 2017 Luptovčiak, Komis, Takáč, Ovečka and Šamaj. This is an openaccess article distributed under the terms of the Creative Commons Attribution License (CC BY). The use, distribution or reproduction in other forums is permitted, provided the original author(s) or licensor are credited and that the original publication in this journal is cited, in accordance with accepted academic practice. No use, distribution or reproduction is permitted which does not comply with these terms. 